\title{
Effect of temperature on induced denitrification - large differences in reaction rate and modified microbiology
}

\author{
FELIX ORTMEYER ${ }^{1}$, DOMINIK BEGEROW ${ }^{1}$, MARCO \\ ALEXANDRE GUERREIRO ${ }^{1}$ AND ANDRE BANNING ${ }^{1,2}$ \\ ${ }^{1}$ Ruhr University Bochum \\ ${ }^{2}$ University College Cork \\ Presenting Author: felix.ortmeyer@rub.de
}

Nitrate $\left(\mathrm{NO}_{3}^{-}\right)$pollution of the resource water is a global problem, which is combined with the challenge of a decreasing and finite $\mathrm{NO}_{3}{ }^{-}$degradation capacity of aquifers. To ensure the availability of clean and healthy drinking water in the future, $\mathrm{NO}_{3}{ }^{-}$concentrations need to be reduced. One of the most effective treatment methods is biological denitrification enhanced by organic carbon. To apply this method in the field and to increase its effectiveness, a better understanding of this treatment is necessary.

This project aims at exploring and comparing the impact of temperature on the effectiveness of induced denitrification by using four organic substances as electron donors: acetate, glucose, ascorbic acid and ethanol are added to circulation columns using sediment without degradation capacity. Each series of experiments is conducted at room temperature (ca. 21 ${ }^{\circ} \mathrm{C}$ ) and typical groundwater temperature in Germany $\left(10^{\circ} \mathrm{C}\right)$, to evaluate the temperature dependency of denitrification rates.

Results show large differences in reaction rates between the two temperature approaches and thus a considerable influence of temperature on denitrification. Contrary to many previous studies, reaction kinetics here does not increase with rising temperature for all electron donors. If ethanol is added, a stronger and more effective $\mathrm{NO}_{3}{ }^{-}$degradation occurs at $10{ }^{\circ} \mathrm{C}$ than at room temperature. In addition, ethanol is clearly the most effective electron donor for biodenitrification in groundwater used in this study while glucose appears to be highly effective in regions with higher groundwater temperatures. Nitrate mitigation is very low with ascorbic acid at both temperatures and a lot of biomass is produced, which leads to clogging. Results of microbial community characterization show a strongly modified denitrifying microbiocenosis influenced by both the addition of different organic substances and groundwater temperature. 